Pure Appl. Chem., Vol. 81, No. 7, pp. 1331-1343, 2009.

doi:10.1351/PAC-REP-08-03-05

(c) 2009 IUPAC, Publication date (Web): 19 May 2009

INTERNATIONAL UNION OF PURE AND APPLIED CHEMISTRY

INORGANIC CHEMISTRY DIVISION*

INTERNATIONAL UNION OF PURE AND APPLIED PHYSICS

IUPAC/IUPAP JOINT WORKING PARTY ON DISCOVERY OF ELEMENTS

\title{
DISCOVERY OF THE ELEMENT WITH ATOMIC NUMBER 112
}

\section{(IUPAC Technical Report)}

\author{
Prepared for publication by \\ ROBERT C. BARBER ${ }^{1, \dagger}$, HEINZ W. GÄGGELER ${ }^{2}$, PAUL J. KAROL ${ }^{3, \S, \ddagger, * *,}$ \\ HIROMICHI NAKAHARA ${ }^{4, \S}$, EMANUELE VARDACI $^{5}$, AND ERICH VOGT ${ }^{6, \S}$ \\ ${ }^{1}$ Department of Physics and Astronomy, University of Manitoba, Manitoba R3T 2N2, Canada; ${ }^{2}$ Paul \\ Scherrer Institute, CH-5232 Villigen, Switzerland; ${ }^{3}$ Department of Chemistry, Carnegie Mellon \\ University, Pittsburgh, PA 15213, USA $;{ }^{4}$ Chemistry Department, Tokyo Metropolitan University, \\ Tokyo 192-03, Japan; ${ }^{5}$ University of Naples "Federico II" and Istituto Nazionale di Fisica Nucleare, \\ Napoli, Italy; ${ }^{6}$ TRIUMF, Vancouver, BC V6T 1W5, Canada
}

*Membership of the Inorganic Chemistry Division Committee for the period 2006-2008 was as follows:

2006-2007: President: A. R. West (UK); Vice President: K. Tatsumi (Japan); Secretary: L. V. Interrante (USA); Titular Members: C. Bianchini (Italy); A. V. Chadwick (UK); T. B. Coplen (USA); M. Leskelä (Finland); R. D. Loss (Australia); J. Reedijk (Netherlands); M. P. Suh (Korea); Associate Members: J. García-Martínez (Spain); N. E. Holden (USA); S. Mathur (Germany); L. A. Oro (Spain); National Representatives: T. Basova (Russia); J. Corish (Ireland); J. Takats (Canada); M. Drabik (Slovakia); T. P. Gajda (Hungary); T. Ding (China/Beijing); V. K. Jain (India).

2008-2009: President: K. Tatsumi (Japan); Vice President: R. D. Loss (Australia); Secretary: L. V. Interrante (USA); Past President: A. R. West (UK); Titular Members: T. Ding (China/Beijing); T. B. Coplen (USA); M. Leskelä (Finland); J. García-Martínez (Spain); L. A. Oro (Spain); J. Reedijk (Netherlands); M. Paik Suh (Korea); Associate Members: A. Chadwick (UK); M. Drabik (Slovakia); N. E. Holden (USA); S. Mathur (Germany); K. Sakai (Japan); J. Takats (Canada); National Representative: T. V. Basova (Russia); A. Bologna Alles (Uruguay); R. Gonfiantini (Italy); P. Karen (Norway); L.-K. Liu (China/Taipei); L. R. Ohrström (Sweden).

\footnotetext{
$\dagger$ Former member of the Transfermium Working Group

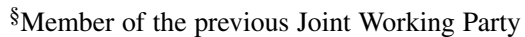

‡Corresponding author: E-mail: pk03@andrew.cmu.edu

**Chair
}

Republication or reproduction of this report or its storage and/or dissemination by electronic means is permitted without the need for formal IUPAC permission on condition that an acknowledgment, with full reference to the source, along with use of the copyright symbol $\odot$, the name IUPAC, and the year of publication, are prominently visible. Publication of a translation into another language is subject to the additional condition of prior approval from the relevant IUPAC National Adhering Organization. 


\title{
Discovery of the element with atomic number 112
}

\section{(IUPAC Technical Report)}

\begin{abstract}
The IUPAC/IUPAP Joint Working Party (JWP) on the priority of claims to the discovery of new elements has reviewed the relevant literature pertaining to several claims. In accordance with the criteria for the discovery of elements previously established by the 1992 IUPAC/IUPAP Transfermium Working Group (TWG), and reiterated by the 1999 and 2003 IUPAC/IUPAP JWPs, it was determined that the 1996 and 2002 claims by the Hofmann et al. research collaborations for the discovery of the element with atomic number 112 at Gesellschaft für Schwerionenforschung (GSI) share in the fulfillment of those criteria. A synopsis of $Z=112$ experiments and related efforts is presented. A subsequent report will address identification of higher- $Z$ elements including those of odd atomic number.
\end{abstract}

Keywords: discovery of element 112; new elements; transfermium; periodic table; heavy elements; island of stability; doubly closed shell; nucleosynthesis; transactinides; transactinoids.

\section{INTRODUCTION}

The working party of independent experts drawn from IUPAC and IUPAP that assigned priority of claims to the discovery of elements 110 and 111 was asked to continue its efforts by addressing more recent results. Not all the members were able to act again, and a new joint working party (JWP) with a membership comprising the authors of this report was formally appointed by the Presidents of IUPAC and IUPAC. Following the previous protocol, laboratories primarily involved in the studies were contacted in August 2005 requesting papers relevant to the discoveries, with the understanding that a working party would be formed to carefully review those materials. The deadline was set as January 2006 for material submitted by claimants. During the course of review, it became apparent to the JWP that more recent results with important bearing on the pending conclusions were completed by the various research groups. Consequently, an ancillary request was formally extended, bringing the deadline to 30 June 2007.

The task of the working party was to review documentation, to make judgments on the priority claims, and to report to the two Unions through Prof. John Corish, former President of the Inorganic Chemistry Division of IUPAC.

\section{COMPOSITION OF THE WORKING PARTY}

Ideally, the membership of the JWP of physicists and chemists with expertise in areas relevant to the synthesis and detection of heavy elements should be as neutral as practical. The prevailing situation with heavy element research, though, now has such a broad collaborative nature to the point where it is becoming challenging to achieve that ideal membership. Accordingly, members of this JWP have agreed to excuse themselves from any recommendation for which there is a potential conflict of interest. 


\section{CRITERIA USED}

The "Criteria that must be satisfied for the discovery of a new chemical element to be recognized" $[1,2]$ established by the IUPAP/IUPAC Transfermium Working Group (TWG) continued to be used as guiding principles. Sections particularly relevant to balancing a sensibly conservative stance with the need for reasonable flexibility continue to be paramount to our deliberations, and this waiver option has been italicized by us in the quoted selection below for emphasis, as was done in the past. Our motivation, as noted previously, is not to set a higher standard for "discovery" than applies elsewhere in science but rather to conform to a uniform, consistent basis for definitive observation and interpretation.

"Discovery of a chemical element is the experimental demonstration, beyond reasonable doubt, of the existence of a nuclide..."

"The TWG realizes that the term 'reasonable doubt' is necessarily somewhat vague... Confirmation demands reproducibility... In the case of the new elements the TWG attaches considerable importance to reproducibility and would indeed like to be able to suggest that no new element should be recognized officially until the data upon which the claim is based have been reproduced, preferably in another laboratory and preferably by a different technique. However, it cannot: ...it would appear unreasonable to apply such a demand of demonstrated reproducibility in all rigidity. We do not believe that recognition of the discovery of a new element should always be held up until the experiment or its equivalent have been repeated, desirable in principle as this may be. However, we would waive this requirement only in cases where the data are of such a nature that no reasonable doubt is possible (for instance for data with a high degree of internal redundancy and of the highest quality), and under circumstances where a repetition of the experiment would imply an unreasonable burden."

As an outcome of previous deliberations, the JWP agreed that it would not be much swayed by arguments that depend heavily on statistics of speculative interpretations; that is, in the absence or near absence of unambiguous identifying characteristics, if the data are not distinguished by quality, clarity, and redundancy, conjectures supported mainly by elimination of alternatives are not sufficient. Furthermore, it is not the intent of the JWP to influence one way or another the otherwise independent refereeing of claims submitted to journals for review. In that regard, as we note later and have emphasized in the past, much more credence is given to work that has already gone through the traditional assessment process as opposed to non-refereed conference proceedings or laboratory reports, to cite common alternatives.

\section{OVERVIEW OF THE DISCOVERY TERRAIN AND APPROACHES}

Figure 1 is a schematic diagram of atomic number $(Z)$ vs. neutron number $(N)$ showing the current status of isotope assignments at the highest values of $Z$ and $N$. "Known" nuclides are shown as filled squares, and recently reported nuclides as open squares. This is the domain being explored by the various research groups and may be described in terms of the synthesis paths invoked by the investigators. The region enclosed on the left is roughly the "cold fusion" product region, achieved, for example, by accelerated ${ }^{70} \mathrm{Zn}$ projectiles fusing with a ${ }^{208} \mathrm{~Pb}$ target (followed by loss of only one or two neutrons through "evaporation"). The region enclosed on the right of the cold fusion product region is roughly the "hot fusion" product zone, reached, for instance, via ${ }^{48} \mathrm{Ca}$ projectiles incident upon an actinide [actinoid] target such as ${ }^{249} \mathrm{Cf}$. These reactions produce compound nuclei with higher excitation energies, resulting in more extensive evaporation of neutrons and possibly even of charged particles. These products may more closely approach the originally hypothesized "island of stability" around the doubly closed shell at ${ }^{298} 114$ represented by the filled diamond. Additionally, there is the claim of a fission-fusion pathway in which, typically, tungsten undergoes high-energy fission induced by relativistic protons 


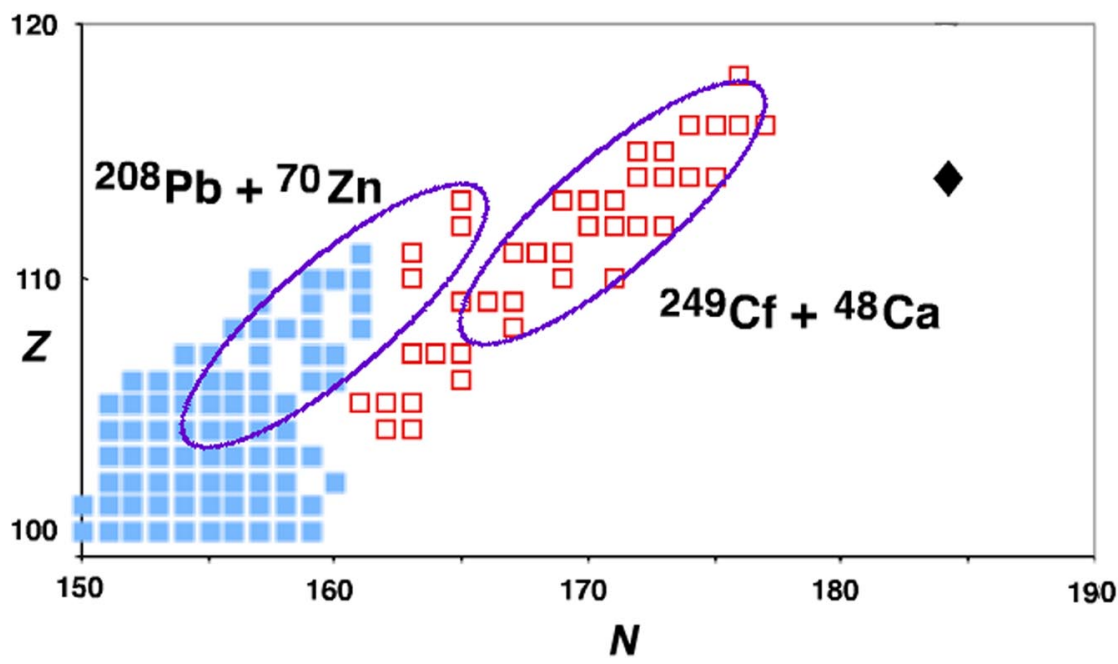

Fig. 1 The filled squares on the $Z$ vs. $N$ grid correspond to "known" nuclides and the open squares to proposed "new" nuclides. The enclosed region on the left is approximately where products from cold fusion (example $\mathrm{Pb}+$ $\mathrm{Zn}$ ) would be and the other enclosed region indicates the potentially reachable nuclides from hot fusion (example $\mathrm{Cf}+\mathrm{Ca}$ ), each from the target-projectile combination, respectively, indicated in the figure. For the filled diamond, see text.

producing, amongst a wide spectrum of primary products, ${ }^{88} \mathrm{Sr}$ that subsequently undergoes a secondary reaction with ${ }^{184} \mathrm{~W}$ within the tungsten target to produce neutron-rich $e k a-\mathrm{Hg},{ }^{272} 112$, for example. The predominant mode of radioactive decay for the proposed new nuclides in Fig. 1 is spontaneous fission and/or $\alpha$-particle emission directed toward the lower left on the $Z$ vs. $N$ diagram. In addition to the motivation to produce and characterize the properties of new heavy elements and isotopes, new knowledge of both nuclear and chemical properties is of great value in testing and in formulating theoretical models for prediction of nuclear stability and chemical properties in as yet unknown regions.

For convenience, the JWP has divided its discussion into two parts, the first dealing with the "cold fusion" pathway and the second with the "hot fusion" approach to synthesis.

\section{DISCOVERY PROFILES}

As in previous reports, we follow the procedures and format for discovery profiles: historical accounts of relevant publications on each element supplemented by our consensual opinion(s) as to the value of the evidence on the basis of the criteria. Our resources were articles submitted by 30 June 2007 by research groups and laboratories in response to formal solicitations by IUPAC. Also, other relevant publications routinely available in research libraries or through modern electronic search techniques were sought. A listing appears at the end of this report. As is customary in scientific analysis, and by rigorous practice now within the JWP, considerably more credence is given to content and date of publications that had been subjected to critical refereeing. Each profile begins with a reprise of the pertinent TWG [2] and JWP [3,4] content, if any. The element atomic number is in boldface followed by sequentially enumerated comment labels. 


\section{Cold fusion}

112; 01 The collaboration of Hofmann et al. [5]

Using the electromagnetic velocity filter SHIP, two chains of fusion-like residues of the reaction of ${ }^{70} \mathrm{Zn}$ with enriched ${ }^{208} \mathrm{~Pb}$ targets were reported. Existence of the first chain was subsequently retracted following re-analysis by Hofmann et al. [6], showing that it was not in the original data. Therefore, only the properties of the second chain are considered. This chain was identified as originating with ${ }^{277} 112$. However, regarding the complete criteria, there is only one redundancy, that assigned to the previously uncharacterized isotope ${ }^{269} \mathrm{Hs}$ that appears in both events; there is no redundancy involving known daughters. The observed alpha leads to the known isotope ${ }^{265} \mathrm{Sg}$, but then a ${ }^{261} \mathrm{Rf} \alpha$-energy of $8.5 \mathrm{MeV}$ was reported that was in significant disagreement with energies known at the time, posing some uncertainty with the assignment. The last alpha in the chain agrees well with that of the known ${ }^{257}$ No descendant but is the sole concordant daughter comparison event of the entire 112 set (see Fig. 2). Recently, a re-analysis [7] of reactions of ${ }^{248} \mathrm{Cm}+{ }^{22} \mathrm{Ne}$ that produced $60{ }^{265} \mathrm{Sg} \rightarrow{ }^{261} \mathrm{Rf} \alpha-\alpha$ chains was reported that supports isomerism in both ${ }^{265} \mathrm{Sg}$ and ${ }^{261} \mathrm{Rf}$. In the latter case, a 3-s lifetime state associated with an $8.51 \mathrm{MeV} \alpha$-particle is substantiated, supporting the Hofmann et al. interpretation.

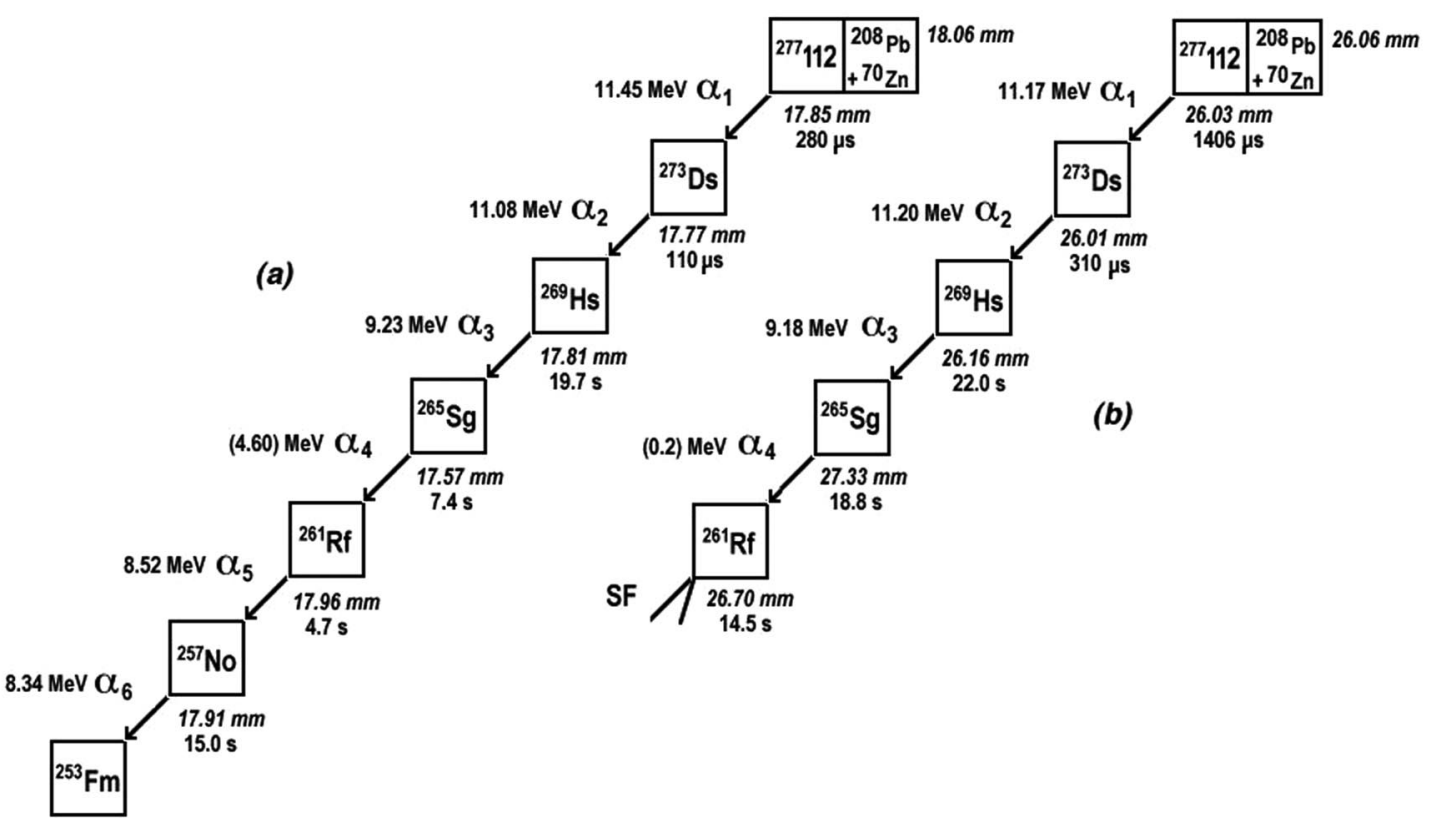

Fig. $2 \alpha$-Particle decay chains observed by the Hofmann collaborations: (a) [5] and (b) [6].

Reference [8] reports one ${ }^{273} \mathrm{Ds} \alpha$-particle with energy $10.85 \mathrm{MeV}$ in agreement with this Hofmann et al. group's $11.08 \mathrm{MeV}$ when resolution is taken into account. There are other chains in ref. [8] noted with lesser confidence but that nevertheless do not provide further redundancy to these results by Hofmann et al.

112; 02 The 2002 collaboration of Hofmann et al. [6]

This collaboration reports on one new chain originating from ${ }^{277} 112$ in the ${ }^{70} \mathrm{Zn}+{ }^{208} \mathrm{~Pb}$ reaction. Hofmann et al. thus have a total of two $\alpha$ - and lifetime chains of events originating with the new isotope, ${ }^{277} 112$ (see Fig. 2). The chains continue to the previously unknown ${ }^{269} \mathrm{Hs}$ for which $\alpha$-energies $(9.2 \mathrm{MeV})$ and lifetimes $(21 \mathrm{~s})$ are similar in both events. The Hofmann et al. chains continue through ${ }^{265} \mathrm{Sg}$, but with no precise $\alpha$-energies. Only the first chain of Hofmann et al. resumes, producing ${ }^{261} \mathrm{Rf}$ 
with an $8.52 \mathrm{MeV} \alpha$ - and $4.7 \mathrm{~s}$ lifetime. As noted previously, the first ${ }^{277} 112$ chain ultimately decays by emitting an $\alpha$-particle and its lifetime is in very good agreement with that for the known isotope ${ }^{257} \mathrm{No}$. The second chain ends with spontaneous fission by ${ }^{261} \mathrm{Rf}$. More recent experiments [9-14], all involving the reaction between ${ }^{26} \mathrm{Mg}$ and ${ }^{248} \mathrm{Cm}$, followed chemical oxidation of the product and its separation presuming Group 8 tetroxide volatility. The decay characteristics consequently implied for ${ }^{269} \mathrm{Hs}$ through $\alpha$-chains connecting with known daughters including ${ }^{261} \mathrm{Rf}$ and ${ }^{257}$ No $[13,14]$ are consistent with the assignment proposed by the Hofmann collaborations for their decay chain first reported in 1996. The intermediate ${ }^{269} \mathrm{Hs}$ had $\alpha$-energies of $9.10 \mathrm{MeV}$ and average lifetime of about $22 \mathrm{~s}$.

\section{2; 03 The collaborations of Morita et al. [16-18]}

Using the RIKEN heavy-ion facility in Japan in conjunction with a very low background detection system, these collaborations reported an identical synthetic route to that pursued by Hofmann et al. These indeed do duplicate two decay chains commencing with ${ }^{277} 112$, proceeding through ${ }^{269} \mathrm{Hs}$ with $\alpha$-energies of $9.2 \mathrm{MeV}$ and terminating at ${ }^{261} \mathrm{Rf}$ by spontaneous fission. Chance misidentification of $\alpha$-emitters is of serious concern in low statistics results. The extremely small background under which these RIKEN measurements were acquired is especially reassuring. The Morita et al. results are a particularly important contribution to the acceptance of the discovery of the element with atomic number 112 and are displayed in the figure below for comparison.

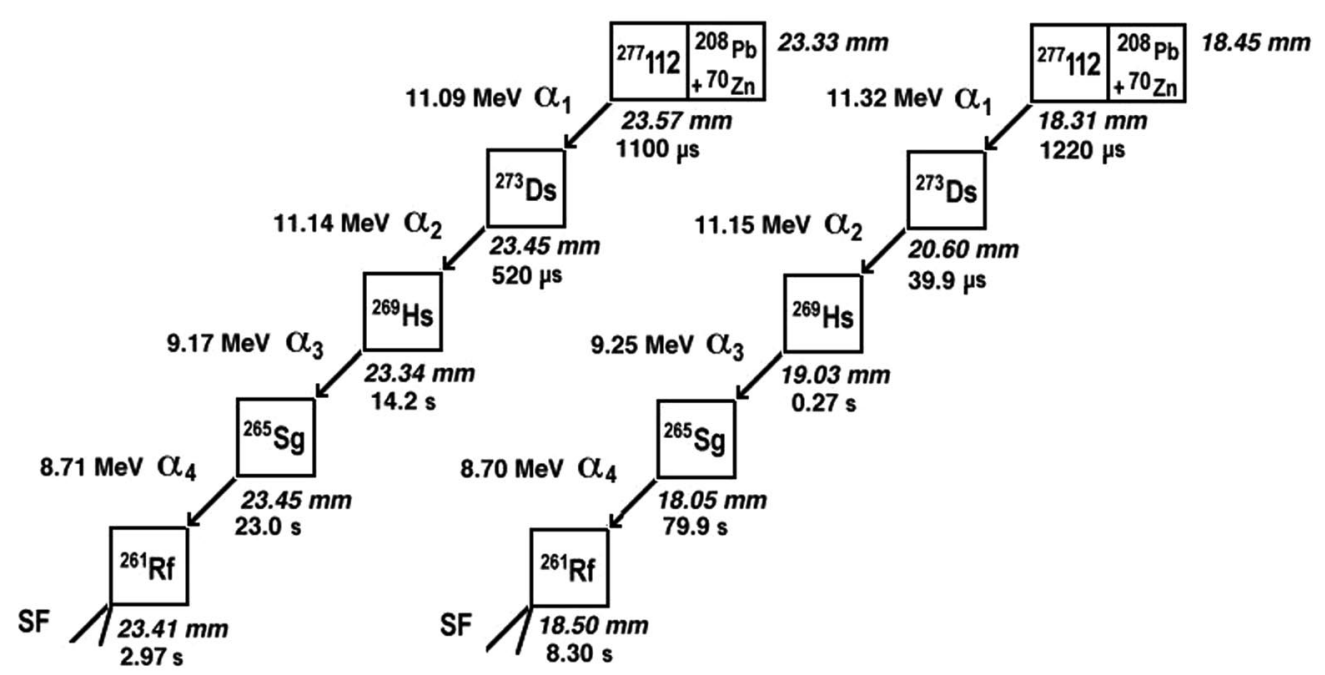

Fig. $3 \alpha$-Particle decay chains observed by the Morita collaboration [18].

JWP ASSESSMENT: The 1996 collaboration of Hofmann et al. [5] combined with the 2002 collaboration of Hofmann et al. [6] are accepted as the first evidence for the synthesis of element with atomic number 112, being supported by subsequent measurements of Morita et al. [16,18], and by assignment of decay properties of likely hassium intermediates $[9,11,13]$ in the decay chain originating from ${ }^{277} 112$.

\section{2; 04-09 The collaborations of Marinov et al. [19-24]}

This collaboration reiterates arguments for their discovery of the element with atomic number 112 through the existence of very long-lived hyper-deformed isomeric states of actinides [actinoids] and transactinides [transactinoids], produced from multi-GeV protons in a thick $\mathrm{W}$ target and, in the case of $e k a-\mathrm{Hg}$, of subsequent spontaneous fission, a very nonspecific indicator. Unusually high fusion crosssections induced by secondary products are required for nuclide formation, each several orders of magnitude beyond known behavior. Results from other research groups that attempted obvious corrobora- 
tion studies using multi-GeV protons incident on a $\mathrm{U}$ target clearly indicated the production path was irreproducible as previously stressed [1,3,4]. The latter refutations have been challenged by Brandt $[18,25]$, a member of the Marinov collaboration, in which he rejects the negative results because the same exact experiment as conducted by Marinov was not followed. However, independent evidence is what "Criteria" (q.v.) demand. Cloning of methodology is an approach that could easily camouflage systematic error.

In his later (second) challenge, Brandt [25] alludes to two lines of evidence for unusually high cross-sections of secondary particles. Even if the JWP accepted his lines of evidence-which it does not-this would not bring the original claim for the discovery of the element with atomic number 112 by the Marinov group any closer to satisfying the criteria for discovery.

The Marinov collaboration also recently claimed discovery [24,26,27] of several long-lived, naturally occurring, very neutron-deficient thorium isomeric states, e.g., ${ }^{210} \mathrm{Th}$ and long-lived isotopes (allegedly Rg) with mass numbers 261 and 265 in natural Au at the sub-ppb level of abundance. These claims are based on mass spectroscopic data where an inductively coupled plasma ion source is used and very low background count rates are observed.

Such instruments are well known to generate ion species that are not readily identified. In particular, the Element 2 manufacturer's brochure* warns that "Even in a sample matrix as simple as ultra pure water (UPW), interferences do exist, especially at low analyte concentration levels". While Marinov et al. argue that multi-hydrogen molecules are excluded on the basis of mass, they have nevertheless identified some other very unusual molecules in their spectra, viz., $\mathrm{PbHe}, \mathrm{AuO}$, and DyArO. Thus, their work does not convincingly demonstrate that the identification of the observed ions is unambiguous and correct. Moreover, they have relied on the manufacturer's specifications, for (1) the relationship between sample concentration and ion current that should be observed, as well as for (2) the background current at the location of the presumed trace peaks. In so doing, they calculate abundances of the trace peaks, relative to the principal peak ${ }^{232} \mathrm{Th}$ of $(1$ to 10$) \times 10-11$. Such an abundance ratio would require that the abundance sensitivity for this mass spectrometer exceeds that of any known mass spectrometer by at least two orders of magnitude and is not accepted.

Species such as ${ }^{210} \mathrm{Th}$, easily accessible through ordinary spallation, are expected to be very fissile. The natural nucleosynthetic path required for production of these nuclides is acknowledged by the Marinov collaboration to be inexplicable. This claim has not been accepted by the scientific community. Furthermore, advocacy by this collaboration of anomalous polonium haloes (ostensibly from $\alpha$-decay) in mica as additional evidence for long-lived superstates without referencing or acknowledging published, long-standing refutations, is misleading. A confluence of atypical phenomena with few significant differences in their measured properties is indispensable for the acceptance of the Marinov collaboration's interpretations.

JWP ASSESSMENT: The Marinov collaborations' thick target yield results remain unresolved. The JWP will not sidestep the Criteria (q.v.) and is not persuaded of the validity of their interpretations vis-à-vis new element production.

\section{Hot fusion}

The second collection of results, most reported to involve ${ }^{283} 112$, arose indisputably subsequent to the Hofmann et al. report. All of these emerge from cross-bombardments interpreted as either direct to the element with atomic number 112 or to even higher $Z$ elements that subsequently decay through the element with atomic number 112. In that regard, the discussion of the ${ }^{283} 112$ results will likely prove to be pivotal in the impending consideration of even heavier elements and deserves careful, early deliberation. Moreover, the history of these studies is a useful venue for demonstrating the rationale for the

\footnotetext{
*Finnegan Element 2, Thermo Electron Corporation.
} 
JWP's necessarily conservative stance in drawing conclusions. To paraphrase the introduction to the most recent publication [28]: three years after the first Hofmann et al. experiments, Dubna reported the production of ${ }^{283} 112$ with a spontaneous fission half life of $3 \mathrm{~min}$ [29]. Subsequent production experiments enabled chemical studies to show the elemental product was not mercury-like. In retrospect, identification of 112 was acknowledged to be tentative because it relied on nonspecific spontaneous fission detection (italics by the JWP). Further experiments indicated a 4-s half life associated with a $9.5-\mathrm{MeV}$ $\alpha$-decay. But production attempts at Berkeley [30] failed to reproduce the observation. Chemistry experiments in Germany failed to observe the element with atomic number 112 [31]. To confound the situation, there was no anchor tying ${ }^{283} 112$ to any known nuclide. Further developments, including an encouraging update, follow.

\section{2; 10-11 The 1998 collaborations of Oganessian et al. [32,33]}

These collaborations used the reactions ${ }^{48} \mathrm{Ca}+{ }^{242} \mathrm{Pu}$ and ${ }^{48} \mathrm{Ca}+{ }^{244} \mathrm{Pu}$, respectively, each to make one observed chain stated to originate with ${ }^{287} 114$ and ${ }^{289} 114$, respectively, which pass through unknown intermediates, ${ }^{283} 112$ and ${ }^{285} 112$, terminating in spontaneous fission at ${ }^{283} 112$ and ${ }^{277} \mathrm{Hs}$, respectively.

\section{2; 12 The Dubna collaboration of Oganessian et al. [29]}

This collaboration used the reaction ${ }^{48} \mathrm{Ca}+{ }^{238} \mathrm{U}$ and reported two events decaying by spontaneous fission with a lifetime of $\approx 2 \mathrm{~min}$ and ascribed to ${ }^{283} 112$. An independent repetition of the same experiment [30] did not show any events, albeit with insufficient sensitivity to disprove the data from [29]. Another independent attempt to follow the chemistry of the element with atomic number 112 produced by the same path led to several events assigned to ${ }^{283} 112$ [34] and following radon-like, i.e., non-mercury-like, behavior.

112; 13 The Oganessian et al. collaborations [35,36]

${ }^{244} \mathrm{Pu}+{ }^{48} \mathrm{Ca}$ in the first case and ${ }^{248} \mathrm{Cm}+{ }^{48} \mathrm{Ca}$ in the second case are used to produce decay chains reported to commence with ${ }^{288} 114$ or ${ }^{292} 116$, respectively, followed by a pair of concordant $\alpha$-decays and assigned to the otherwise unknown ${ }^{284} 112$, terminating in spontaneous fission of unknown ${ }^{280} \mathrm{Ds}$. The decay energies and lifetimes of three events for ${ }^{284} 112$ are internally redundant, but no docking to recognized nuclei occurs. In the ${ }^{244} \mathrm{Pu}+{ }^{48} \mathrm{Ca}$ study, another event originating with ${ }^{289} 114$ followed by a chain observed reportedly through ${ }^{285} 112$ and ${ }^{281}$ Ds terminates with spontaneous fission at ${ }^{277} \mathrm{Hs}$, all unknown. The experiment in [36] is discussed further in [37,38].

\section{2; 14 The 2003 collaboration of Oganessian et al. [39]}

This collaboration sought to reproduce the 1998 claims to ${ }^{283} 112$ synthesis by [29]. A 29-day irradiation using a ${ }^{48} \mathrm{Ca}$ beam with a mid-target energy of $231 \mathrm{MeV}$ produced no relevant decay chains, in common with the results of [27]. A second irradiation lasting 15 days at an energy of $234 \mathrm{MeV}$ produced two spontaneous fission events with a lifetime of about 7 min consistent with the 1998 values claimed for $e k a$-Hg-daughter ${ }^{279} \mathrm{Ds}$ decay. No $\alpha$-decay branches were measured.

\section{2; 15 The 2003 collaboration of Oganessian et al. [40]}

This collaboration utilized the ${ }^{48} \mathrm{Ca}$ reactions with both ${ }^{244} \mathrm{Pu}$ and ${ }^{245} \mathrm{Cm}$ to reach $Z=114$ and $Z=116$, respectively. Three observed chains (one from $\mathrm{Pu}$, two from $\mathrm{Cm}$ ) decay in $\approx 9 \mathrm{~s}$ by $9.5 \mathrm{MeV} \alpha$-emission, all events being in agreement and assigned to ${ }^{283} 112$. The daughter nuclei in each case decay by spontaneous fission.

\section{2; 16 The 2004 collaboration of Oganessian et al. [41]}

This collaboration again generated ${ }^{48} \mathrm{Ca}$-induced fusion reactions with $\mathrm{U}, \mathrm{Pu}$, and $\mathrm{Cm}$ targets to produce $Z=112,114$ and $Z=116$ isotopes. Eighteen observed chains pass through ${ }^{283} 112$ which decay in $\approx 4 \mathrm{~s}$ by $9.54 \pm 0.06 \mathrm{MeV} \alpha$-emission leading to ${ }^{279} \mathrm{Ds}$ daughter nuclei decaying by spontaneous fission with a 0.2 -s lifetime. One chain had, instead, an $\alpha$-decay energy of $9.7 \mathrm{MeV}$. 


\section{2; 17 The 2005 collaboration of Oganessian et al. [42]}

This collaboration sought to synthesize superheavy elements by ${ }^{48} \mathrm{Ca}$-induced fusion reactions with ${ }^{249} \mathrm{Cf}$ and ${ }^{245} \mathrm{Cm}$. One decay chain in the latter case reported an intermediate ${ }^{283} 112$ step with $\alpha$-particle decay of $9.57 \mathrm{MeV}$, in excellent agreement with the previous accumulation of results, but with a lifetime of only $35 \mathrm{~ms}$. The daughter ${ }^{279} \mathrm{Ds}$ decayed in $0.7 \mathrm{~s}$ by $9.7 \mathrm{MeV} \alpha$-emission in agreement with [29]. This particular chain terminated after $1.6 \mathrm{~h}$ with spontaneous fission attributed to ${ }^{267} \mathrm{Rf}$.

\section{2; 18 The GSI collaboration of Hofmann et al. [43]}

This collaboration sought to re-attempt the synthesis of the element with atomic number 112 by the ${ }^{48} \mathrm{Ca}+{ }^{238} \mathrm{U}$ fusion reaction that previously had evinced contradictory results $[28,30,31,34,44,45]$ and reported two events with $\alpha$-energies of $9.52 \mathrm{MeV}$ ascribed to 283112 and two other events following instead a spontaneous fission branch. The ${ }^{283} 112$ lifetime for the four events was $10 \mathrm{~s}$.

JWP ASSESSMENT: The more recent Dubna collaborations have performed careful, high-quality studies whose acknowledgment as synthesis of $Z=112$ nuclides, especially ${ }^{283} 112$, given the significant redundancies including an independent investigation at GSI, appears very likely. Although there remain unsecured connections to known descendants, we note that among the criteria established by the TWG is the following, addressing cross-bombardments: "Comparison of the probability of production of ${ }^{\mathrm{A}} \mathrm{Z}$ in different combinations of [target] and [projectile] can sometimes give valuable assignment criteria." Collectively, the Dubna and GSI results above $(112 ; 15-18)$ find reproducible decay characteristics from ${ }^{48} \mathrm{Ca}$ fusion studies on $\mathrm{U}, \mathrm{Pu}$, and $\mathrm{Cm}$ targets that persuasively support the assignment of 283112 .

\section{COMMENTS}

The element with atomic number 112 has been reviewed and assigned priority of discovery. The decision is justified not only on the basis of the quality of the work and replication, but especially on the fact that familiar nuclides were identified as part of the detection sequence(s) providing an anchor positioning the chain accordingly. In the absence of such cross-checks, as happens with more isolated regions of the nuclide chart evident in much of the recent, more extensive element searches, the JWP feels the conservative stance of waiting for independent experimental confirmation is both prudent and defendable as experience has shown.

The TWG recognized and the JWP strongly continues to agree that there will be situations in which an early paper did not, at the time, convey conviction of discovery, but that later investigations revealed to have been correct. The existence of the element in question is then definitely established by subsequent work following the lead of the early paper, as was the case here. Overlap with the prior results or fully characterizing the identity of a descendant in a chain are among the types of co-participation that would need to be carefully taken into account. The TWG felt it would clearly be wrong to assign absolute priority to that early paper, but that it would be appropriate to weigh its seminal importance. Any future decision motivated by new results should keep this in mind. The JWP encourages the laboratories to continue to pursue the production and characterization of new elements with the growing vigor and skill evident in its efforts to date.

\section{SUMMARY OF JWP CONCLUSIONS}

The IUPAC/IUPAP JWP performed a critical review of the various claims to discovery of the transroentgenium element $Z=112$. Experimental techniques involving heavy-ion fusion, fusion product separation, position-sensitive $\alpha$-particle measurements, and low background continue to improve their selectivity for these extremely rare events. In concordance with the criteria established for validating claims, the JWP has agreed that the priority of the Hofmann et al. 1996 [5] and 2002 [6] collaborations' discovery of the element with atomic number 112 at GSI is acknowledged. As before, the JWP deci- 
sions are of a delicate nature. It must be recognized that there is no intent by the JWP to suggest invalidation of any of the other results. In addition, despite efforts by the Marinov et al. collaboration using atypical studies in conjunction with provisional theory to reinforce their claim to the element with atomic number 112, we conclude that the results of secondary interactions involving hyper-deformed products of long lifetime and high production probability remain unconvincing, all aspects of which require independent corroborative investigation.

\section{REFERENCES}

1. A. H. Wapstra. Pure Appl. Chem. 63, 879 (1991) and also as ref. [2].

2. R. C. Barber, N. N. Greenwood, A. Z. Hrynkiewics, Y. P. Jeannin, M. Lefort, M. Sakai, I. Uleuhla, A. H. Wapstra, D. H. Wilkinson. Prog. Part. Nucl. Phys. 29, 453 (1992).

3. P. J. Karol, H. Nakahara, B. W. Petley, E. Vogt. Pure Appl. Chem. 73, 959 (2001).

4. P. J. Karol, H. Nakahara, B. W. Petley, E. Vogt. Pure Appl. Chem. 75, 1601 (2003).

5. S. Hofmann, V. Ninov, F. P. Hessberger, P. Armbruster, H. Folger, G. Münzenberg, H. J. Schött, A. G. Popeko, A. V. Yeremin, S. Saro, R. Janik, M. Leino. Z. Phys. A 354, 229 (1996).

6. S. Hofmann, F. P. Hessberger, D. Ackermann, G. Münzenberg, S. Antalic, P. Cagarda, B. Kindler, J. Kojouharova, M. Leino, B. Lommel, R. Mann, A. G. Popeko, S. Reshitko, S. Saro, J. Uusitalo, A. V. Yeremin. Eur. Phys. J. A 14, 147 (2002).

7. (a) Ch. E. Düllmann, A. Türler. Phys. Rev. C 77, 064320 (2008); (b) Ch. E. Düllmann, A. Türler. erratum Phys. Rev. C 78, 029901 (2008).

8. Y. A. Lazarev, Y. V. Lobanov, Y. T. Oganessian, V. K. Utyonkov, F. S. Abdullin, A. N. Polyakov, J. Rigol, I. V. Shirokovsky, Y. S. Tsyganov, S. Iliev, V. G. Subbotin, A. M. Sukhov, G. V. Buklanov, B. N. Gikal, V. B. Kutner, A. N. Mezentsev K. Subotic, J. F. Wild, R. W. Lougheed, K. J. Moody. Phys. Rev. C 54, 620 (1996).

9. Ch. E. Düllmann, W. Brüchle, R. Dressler, K. Eberhardt, B. Eichler, R. Eichler, H. W. Gäggeler, T. N. Ginter, F. Glaus, K. E. Gregorich, D. C. Hoffman, E. Jäger, D. T. Jost, U. W. Kirbach, D. M. Lee, H. Nitsche, J. B. Patin, V. Pershina, D. Piguet, Z. Qin, M. Schädel, B. Schausten, E. Schimpf, H.-J. Schött, S. Soverna, R. Sudowe, P. Thörle, S. N. Timohkin, N. Trautmann, A. Türler, A. Vahle, G. Wirth, A. B. Yakushev, P. M. Zielinski. Nature 418, 859 (2002).

10. Ch. E. Düllmann, R. Dressler, H. W. Gäggeler, F. Glaus, D. T. Jost, D. Piguet, S. Soverna, A. Türler, W. Brüchle, R. Eichler, E. Jäger, V. Pershina, M. Schädel, B. Schausten, E. Schimpf, H.-J. Schött, G. Wirth, K. Eberhardt, P. Thörle, N. Trautmann, T. N. Ginter, K. E. Gregorich, D. C. Hoffman, U. W. Kirbach, D. M. Lee, H. Nitsche, J. B. Patin, R. Sudowe, P. M. Zielinski, S. N. Timohkin, A. B. Yakushev, A. Vahle, Z. Qin. Czech. J. Phys. 53, A291 (2003).

11. A. Türler, Ch. E. Düllmann, H. W. Gäggeler, U. W. Kirbach, A. B. Yakushev, M. Schädel, W. Brüchle, R. Dressler, K. Eberhardt, B. Eichler, R. Eichler, T. N. Ginter, F. Glaus, K. E. Gregorich, D. C. Hoffman, E. Jäger, D. T. Jost, D. M. Lee, H. Nitsche, J. B. Patin, V. Pershina, D. Piguet, Z. Qin, B. Schausten, E. Schimpf, H.-J. Schött, S. Soverna, R. Sudowe, P. Thörle, S. N. Timohkin, N. Trautmann, A. Vahle, G. Wirth, P. M. Zielinski. Eur. Phys. J. A 17, 505 (2003).

12. H. W. Gäggeler, W. Brüchle, Ch. E. Düllmann, R. Dressler, K. Eberhardt, B. Eichler, R. Eichler, C. M. Folden, T. N. Ginter, F. Glaus, K. E. Gregorich, F. Haenssler, D. C. Hoffman, E. Jäger, D. T. Jost, U. W. Kirbach, J. V. Kratz, H. Nitsche, J. B. Patin, V. Pershina, D. Piguet, Z. Qin, U. Rieth, M. Schädel, B. Schausten, E. Schimpf, H.-J. Schött, S. Soverna, R. Sudowe, P. Thörle, N. Trautmann, A. Türler, A. Vahle, P. A. Wilk, G. Wirth, A. B. Yakushev, A. von Zweidorf. Proc. $8^{\text {th }}$ Int. Conf. on Nucleus-Nucleus Collisions, Moscow, Russia (2003); Nucl. Phys. A734, 208 (2004). 
13. J. Dvorak, W. Brüchle, M. Chelnokov, R. Dressler, Ch. E. Düllmann, K. Eberhardt, V. Gorshkov, E. Jäger, R. Krücken, A. Kuznetsov, Y. Nagame, F. Nebel, Z. Novackova, Z. Qin, M. Schädel, B. Schausten, E. Schimpf, A. Semchenkov, P. Thörle, A. Türler, M. Wegrzecki, B. Wierczinski, A. Yakushev, A. Yeremin. Phys. Rev. Lett. 97, 242501 (2006).

14. J. Dvorak, W. Brüchle, M. Chelnokov, Ch. E. Düllmann, Z. Dvorakova, K. Eberhardt, E. Jäger, R. Krücken, A. Kuznetsov, Y. Nagame, F. Nebel, K. Nishio, R. Perego, Z. Qin, M. Schädel, B. Schausten, E. Schimpf, R. Schuber, A. Semchenkov, P. Thörle, A. Türler, M. Wegrzecki, B. Wierczinski, A. Yakushev, A. Yeremin. Phys. Rev. Lett. 100, 132503 (2008).

15. A. von Zweidorf, R. Angert, W. Brüchle, S. Bürger, K. Eberhardt, R. Eichler, H. Hummrich, E. Jäger, H.-O. Kling, J. V. Kratz, B. Kuczewski, G. Langrock, M. Mendel, U. Rieth, M. Schädel, B. Schausten, E. Schimpf, P. Thörle, N. Trautmann, K. Tsukada, N. Wiehl, G. Wirth. Radiochim. Acta 92, 855 (2004).

16. K. Morita, K. Morimoto, D. Kaji, T. Akiyama, S. Goto, H. Haba, E. Ideguchi, H. Koura, H. Kudo, T. Ohnishi, A. Ozawa, T. Suda, K. Sueki, H. Xu, T. Yamaguchi, A. Yoneda, A. Yoshida, Y.-L. Zhao. RIKEN Accel. Prog. Rep. 38, 69 (2005).

17. K. Morita. Proc. of the International Symp. on Exotic Nuclei, EXON 2004, Peterhof, Russia, World Scientific, Singapore, 188 (2005).

18. K. Morita, K. Morimoto, D. Kaji, T. Akiyama, S. Goto, H. Haba, E. Ideguchi, K. Katori, H. Koura, H. Kudo, T. Ohnishi, A. Ozawa, T. Suda, K. Sueki, F. Tokanai, T. Yamaguchi, A. Yoneda, A. Yoshida, J. Phys. Soc. Jpn. 76, 043201 (2007).

19. A. Marinov, S. Gelberg, D. Kolb, R. Brandt, A. Pape. Int. J. Mod. Phys. E 12, 661 (2003).

20. A. Marinov, S. Gelberg, D. Kolb, R. Brandt, A. Pape. Phys. Atom. Nucl. 66, 1137 (2003)

21. R. Brandt. Kerntechnik 70,170 (2005).

22. D. Kolb, A. Marinov, G. W. A. Newton, R. Brandt. Kerntechnik 70, 167 (2005).

23. A. Marinov, I. Rodushkin, A. Pape, Y. Kashiv, L. Halicz, I. Segal, A. Pape, R. Gentry, H. W. Miller, D. Kolb, R. Brandt. arXiv: nucl-ex/0605008 (2006).

24. A. Marinov, I. Rodushkin, A. Pape, Y. Kashiv, D. Kolb, R. Brandt, R. Gentry, H. W. Miller, L. Halicz, I. Segal. (unpublished, submitted to Phys. Rev. Lett. 2007).

25. R. Brandt. Phys. Part. Nucl. 39, 259 (2008).

26. A. Marinov, I. Rodushkin, Y. Kashiv, L. Halicz, I. Segal, A. Pape, R. Gentry, H. Miller, D. Kolb, R. Brandt. Phys. Rev. C 76, 021303 (2007).

27. A. Marinov, I. Rodushkin, D. Kolb, A. Pape, Y. Kashiv, R. Brandt, R.V. Gentry, H. W. Miller. Third Int. Conf. on the Chem. and Phys. of the Transactinide Elements (TAN07), Davos, Switzerland, 65 (2007).

28. R. Eichler, N. V. Aksenov, A. V. Belozerov, G. A. Bozhikov, V. I. Chepigin, S. N. Dmitriev, R. Dressler, H. W. Gäggeler, V. A. Gorshkov, F. Haenssler, M. G. Itkis, A. Laube, V. Ya. Lebedev, O. N. Malyshev, Yu. Ts. Oganessian, O. V. Petrushkin, D. Piguet, P. Rasmussen, S. V. Shishkin, A. V. Shutov, A. I. Svirikhin, E. E. Tereshatov, G. K. Vostokin, M. Wegrzecki, A. V. Yeremin. Nature 447, 72 (3 May 2007).

29. Yu. Ts. Oganessian, A. V. Yeremin, G. G. Gulbekian, S. L. Bogomolov, V. I. Chepigin, B. N. Gikal, V. A. Gorshkov, M. G. Itkis, A. P. Kabachenko, V. B. Kutner, A. Yu. Lavrentev, O. N. Malyshev, A. G. Popeko, J. Rohac, R. N. Sagaidak, S. Hofmann, G. Münzenberg, M. Veselsky, S. Saro, N. Iwasa, K. Morita. Eur. Phys. J. A 5, 63 (1999).

30. W. Loveland, K. E. Gregorich, J. B. Patin, D. Peterson, C. Rouki, P. M. Zielinski, K. Aleklett. Phys. Rev. C 66, 044617-1 (2002). 
31. R. Eichler, W. Brüchle, R. Buda, S. Burger, R. Dressler, Ch. E. Düllmann, J. Dvorak, K. Eberhardt, B. Eichler, C. M. Folden III, H. W. Gäggeler, K. E. Gregorich, F. Haenssler, D. C. Hoffman, H. Hummrich, E. Jäger, J. V. Kratz, B. Kuczewski, D. Liebe, D. Nayak, H. Nitsche, D. Piguet, Z. Qin, U. Rieth, M. Schädel, B. Schausten, E. Schimpf, A. Semchenkov, S. Soverna, R. Sudowe, N. Trautmann, P. Thörle, A. Türler, B. Wierczinski, N. Wiehl, P. A. Wilk, G. Wirth, A. B. Yakushev, A. von Zweidorf. Radiochim. Acta 94, 181 (2006).

32. Yu. Ts. Oganessian, A. V. Yeremin, A. G. Popeko, S. L. Bogomolov, G. V. Buklanov, M. L. Chelnokov, V. I. Chepigin, B. N. Gikal, V. A. Gorshkov, G. G. Gulbekian, M. G. Itkis, A. P. Kabachenko, A. Yu. Lavrentev, O. N. Malyshev, J. Rohac, R. N. Sagaidak, S. Hofmann, S. Saro, G. Giardina, K. Morita. Nature 400, 242 (1999).

33. Yu. Ts. Oganessian, V. K. Utyonkov, Yu. V. Lobanov, F. Sh. Abdullin, A. N. Polyakov, I. V. Shirokovsky, Yu. S. Tsyganov, G. G. Gulbekian, S. L. Bogomolov, B. N. Gikal, A. N. Mezentsev, S. Iliev, V. G. Subbotin, A. M. Sukhov, O. V. Ivanov, G. V. Buklanov, K. Subotic, M. G. Itkis, K. J. Moody, J. F. Wild, N. J. Stoyer, M. A. Stoyer, R. W. Lougheed. Phys. Rev. Lett. 83, 3154 (1999).

34. A. B. Yakushev, I. Zvara, Yu. Ts. Oganessian, A. V. Belozerov, S. N. Dmitriev, B. Eichler, S. Hübener, E. A. Sokol, A. Türler, A. V. Yeremin, G. V. Buklanov, M. L. Chelnokov, V. I. Chepigin, V. A. Gorshkov, A. V. Gulyaev, V. Ya. Lebedev, O. N. Malyshev, A. G. Popeko, S. Soverna, Z. Szeglowski, S. N. Timokhin, S. P. Tretyakova, V. M. Vasko, M. G. Itkis. Radiochim. Acta 91, 433 (2003).

35. Yu. Ts. Oganessian, V. K. Utyonkov, Yu. V. Lobanov, F. Sh. Abdullin, A. N. Polyakov, I. V. Shirokovsky, Yu. S. Tsyganov, G. G. Gulbekian, S. L. Bogomolov, B. N. Gikal, A. N. Mezentsev, S. Iliev, V. G. Subbotin, A. M. Sukhov, O. V. Ivanov, G. V. Buklanov, K. Subotic, M. G. Itkis, K. J. Moody, J. F. Wild, N. J. Stoyer, M. A. Stoyer, R. W. Lougheed. Phys. Rev. C 62, 041604/1 (2000).

36. Yu. Ts. Oganessian, V. K. Utyonkov, Yu. V. Lobanov, F. Sh. Abdullin, A. N. Polyakov, I. V. Shirokovsky, Yu. S. Tsyganov, G. G. Gulbekian, S. L. Bogomolov, B. N. Gikal, A. N. Mezentsev, S. Iliev, V. G. Subbotin, A. M. Sukhov, O. V. Ivanov, G. V. Buklanov, K. Subotic, M. G. Itkis, K. J. Moody, J. F. Wild, N. J. Stoyer, M. A. Stoyer, R. W. Lougheed. Phys. Atom. Nucl. 63, 1679 (2000).

37. Yu. Ts. Oganessian, V. K. Utyonkov, K. J. Moody. Phys. Atom. Nucl. 64, 1349 (2001).

38. Yu. Ts. Oganessian, V. K. Utyonkov, Yu. V. Lobanov, F. Sh. Abdullin, A. N. Polyakov, I. V. Shirokovsky, Yu. S. Tsyganov, G. G. Gulbekian, S. L. Bogomolov, B. N. Gikal, A. N. Mezentsev, S. Iliev, V. G. Subbotin, A. M. Sukhov, O. V. Ivanov, G. V. Buklanov, K. Subotic, M. G. Itkis, K. J. Moody, J. F. Wild, N. J. Stoyer, M. A. Stoyer, R. W. Lougheed, C. A. Laue, Ye. A. Karelin, A. N. Tatarinov. Phys. Rev. C 63, 011301/1 (2001).

39. Y. T. Oganessian, A. V. Belozerov, A. V. Yeremin, A. G. Popeko, O. N. Malyshev, A. V. Belozerov, G. V. Buklanov, L. Chelnokov, V. I. Chepigin, V. A. Gorshkov, S. Hofmann, M. G. Itkis, A. P. Kabachenko, B. Kindler, G. Münzenberg, R. N. Sagaidak, S. Saro, H.-J. Schött, B. Streicher, A. V. Shutov, A. I. Svirikhin, G. K. Vostokin. Eur. Phys. J. A 19, 3 (2004)

40. Yu. Ts. Oganessian, V. K. Utyonkov, Yu. V. Lobanov, F. Sh. Abdullin, A. N. Polyakov, I. V. Shirokovsky, Yu. S. Tsyganov, G. G. Gulbekian, S. L. Bogomolov, B. N. Gikal, A. N. Mezentsev, S. Iliev, V. G. Subbotin, A. M. Sukhov, A. A. Voinov, G. V. Bogomolov, K. Subotic, V. I. Zagrebaev, M. G. Itkis, J. B. Patin, K. J. Moody, J. F. Wild, M. A. Stoyer, N. J. Stoyer, D. A. Shaughnessy, J. M. Kenneally, R. W. Lougheed. Phys. Rev. C 69054607 (2004). 
41. Yu. Ts. Oganessian, V. K. Utyonkov, Yu. V. Lobanov, F. Sh. Abdullin, A. N. Polyakov, I. V. Shirokovsky, Yu. S. Tsyganov, G. G. Gulbekian, S. L. Bogomolov, B. N. Gikal, A. N. Mezentsev, S. Iliev, V. G. Subbotin, A. M. Sukhov, A. A. Voinov, G. V. Bogomolov, K. Subotic, V. I. Zagrebaev, M. G. Itkis, J. B. Patin, K. J. Moody, J. F. Wild, M. A. Stoyer, N. J. Stoyer, D. A. Shaughnessy, J. M. Kenneally, P. A. Wilk, R. W. Lougheed, R. I. Il'kaev, S. P. Vesnovskii. Phys. Rev. C 70, 064609 (2004).

42. Yu. Ts. Oganessian, V. K. Utyonkov, Yu. V. Lobanov, F. Sh. Abdullin, A. N. Polyakov, R. N. Sagaidak, I. V. Shirokovsky, Yu. S. Tsyganov, A. A. Voinov, G. G. Gulbekian, S. L. Bogomolov, B. N. Gikal, A. N. Mezentsev, S. Iliev, V. G. Subbotin, A. M. Sukhov, K. Subotic, V. I. Zagrebaev, G. K. Vostokiin, M. G. Itkis, K. J. Moody, J. B. Patin, D. A. Shaughnessy, M. A. Stoyer, N. J. Stoyer, P. A. Wilk, J. M. Kenneally, J. H. Landrum, J. F. Wild, R. W. Lougheed. Phys. Rev. C 74, 044602 (2006).

43. S. Hofmann, D. Ackermann, S. Antalic, H. G. Burkhard, V. F. Comas, R. Dressler, Z. Gan, S. Heinz, J. A. Heredia, F. P. Heßberger, J. Khuyagbaatar, B. Kindler, I. Kojouharov, P. Kuusiniemi, M. Leino, B. Lommel, R. Mann, G. Münzenberg, K. Nishio, A. G. Popeko, S. Saro, H. J. Schött, B. Streicher, B. Sulignano, J. Uusitalo, M. Venhart, A. V. Yeremin. Eur. Phys. J. A 32, 251 (2007).

44. A. B. Yakushev, G. V. Bulkanov, M. L. Chelnokov, V. I. Chepigin, S. N. Dmitriev, V. A. Gorshkov, S. Hübener, V. Ya. Lebedev, O. N. Malyshev, Yu. Ts. Oganessian. Radiochim. Acta 89, 743 (2001).

45. K. E. Gregorich, W. Loveland, D. Peterson, P. M. Zielinski, S. L. Nelson, Y. H. Chung, Ch. E. Düllmann, C. M. Folden III, K. Aleklett, R. Eichler, D. C. Hoffman, J. P. Omtvedt, G. K. Pang, J. M. Schwantes, S. Soverna, P. Sprunger, R. Sudowe, R. E. Wilson, H. Nitsche. Phys. Rev. C 72, 014605 (2005). 